\title{
Red Listing the world's tree species: a review of recent progress
}

\author{
A. C. Newton ${ }^{1, *}$, S. Oldfield ${ }^{2}$ \\ ${ }^{1}$ Centre for Conservation Ecology and Environmental Change, School of Conservation Sciences, Bournemouth University, \\ Talbot Campus, Poole, Dorset BH12 5BB, UK \\ ${ }^{2}$ Botanic Gardens Conservation International, Descanso House, 199 Kew Road, Richmond, Surrey TW9 3BW, UK
}

\begin{abstract}
The IUCN (International Union for Conservation of Nature) Red List of Threatened Spe$\operatorname{cies}^{\mathrm{TM}}(\mathrm{RL})$ is widely recognised as an authoritative assessment of the conservation status of species, yet its coverage is uneven and incomplete. Trees account for approximately $20 \%$ of taxa currently included, but most of these were listed a decade ago. Over the last $10 \mathrm{yr}$, only 879 taxa have been added to the RL database, representing $11 \%$ of the number listed in 1998 . However, progress has not been as limited as these data suggest. Ten recent assessments of different groups of trees are profiled, and the lessons learned from these assessments are summarised. In total, these assessments have evaluated $>2500$ tree taxa, but only a fraction of these have been added to the RL database, raising concerns about the process of data management. Results indicated that a mean of $42 \%$ taxa were classified as threatened. Information on the status and distribution of most tree species is severely lacking, a situation compounded by taxonomic confusion in many groups. As a result, RL assessments will continue to be highly dependent on expert knowledge originating from herbarium data, which, as demonstrated here, tends to result in a relatively high proportion of taxa being listed under RL Criteria B1 and B2. Given this situation, attempts to use the RL to support global monitoring of biodiversity appear premature, and much greater support needs to be given to collection of primary field data and expert knowledge to accurately ascertain the current status of the world's threatened tree species.
\end{abstract}

KEY WORDS: Extinction risk - IUCN · Red List - Threatened species · Forest - Conservation · Biodiversity loss

Resale or republication not permitted without written consent of the publisher

\section{INTRODUCTION}

The IUCN (International Union for Conservation of Nature) Red List of Threatened Species ${ }^{\mathrm{TM}}$ (henceforth referred to as the RL) is widely recognised to be the most authoritative global assessment of the conservation status of species (Lamoreux et al. 2003, Rodrigues et al. 2006, Hoffmann et al. 2008, this Theme Section). The RL has been widely used to inform conservation policies and legislation, to inform the design of protected area networks, to support environmental monitoring and reporting, and to prioritise areas for conservation action (Possingham et al. 2002, Miller et al. 2007, Hoffmann et al. 2008). The RL is used by the Global Environment Facility (GEF) to allocate financial resources (Hoffmann et al. 2008) and also informs en- vironmental assessments such as the Global Forest Resources Assessment (GFRA) coordinated by the Food and Agriculture Organization (FAO 2006) and the Millennium Ecosystem Assessment (Hassan et al. 2005). Although principally designed to evaluate the extinction risk of individual species throughout their ranges, increasingly the IUCN criteria are also being used to develop regional, national and local lists of threatened species (Miller et al. 2007). In addition, recent efforts have focused on use of the RL to develop an indicator (the Red List Index, RLI) suitable for monitoring progress towards the 2010 biodiversity target (Butchart et al. 2004, 2005, 2007, Baillie et al. 2008), a global-scale policy commitment (Mace \& Baillie 2007).

Given the widespread use of the RL to inform conservation policies and their implementation, there is a need 
to ensure that it incorporates reliable assessments of a broad range of taxa. However, it is widely recognised that the taxonomic and geographic coverage of the RL is uneven and suffers from a number of biases. For example, whereas all bird species have been assessed using the RL Categories and Criteria on 4 occasions since 1988 , only around $2 \%$ of all species described worldwide from all taxonomic groups have been assessed (Hoffmann et al. 2008). With respect to plant species, the situation is little better; Nic Lughadha et al. (2005) estimated that approximately $3 \%$ of all known plant species have been assessed. Hoffmann et al. (2008) indicate that only 2 plant groups, namely cycads (Donaldson 2003) and conifers (Farjon et al. 1993, Farjon \& Page 1999) have been comprehensively assessed to date. Nic Lughadha et al. (2005) highlight the fact that most of the plant species currently included in the RL originate from a single project, the 'World List of Threatened Trees' (Oldfield et al. 1998), which provided a first RL assessment for around 8000 tree taxa.

Given that a decade has now passed since the publication of Oldfield et al. (1998), it is timely to consider the subsequent progress in the Red Listing of tree species. The present paper provides a brief overview of recent assessment activities, then examines the lessons that have been learned about the RL process, specifically in relation to this socio-economically and ecologically important group of plants. Potential future directions for the Red Listing of tree species are then explored in the context of strengthening the RL and the process by which it is produced.

\section{THE IUCN RED LISTING PROCESS}

A brief summary of how RL assessments are performed is provided here as background; for further details, see IUCN (2001). During RL assessments, species are assigned to 1 of a series of categories by applying 5 quantitative criteria, which have undergone a series of developments in order to increase their objectivity, transparency and repeatability (Mace \& Lande 1991, IUCN 2001). Criteria A is based on declining population size, either in the past, present, or projected in the future, Criteria B on geographic range size, together with fragmentation, continuing decline, and/or extreme fluctuations, Criteria $\mathrm{C}$ on small population size, with continuing decline, high proportion in 1 subpopulation, and/or extreme fluctuations, Criteria $\mathrm{D}$ on very small or restricted population size, and Criteria E on quantitative analysis of extinction risk (IUCN 2001). Taxa that meet the appropriate threshold for at least 1 of 5 criteria may be categorised as Critically Endangered (CR), Endangered (EN), or Vulnerable (VU); those failing to meet the thresholds may be cate- gorized as Near Threatened (NT), Least Concern (LC), or Data Deficient (DD) (IUCN 2001). The results of RL assessments, after checking by RL authorities, are made available via an online database (www.redlist. org) (IUCN 2007).

\section{CURRENT STATUS OF TREE SPECIES ON THE IUCN RED LIST}

To provide a summary of the current status of the RL in relation to tree species, the online RL database (IUCN 2007) was queried. When accessed on 15 July 2008, the database included 13059 taxa (including species, subspecies and varieties) listed under the Kingdom Plantae, out of a total of 43470 taxa for all taxonomic groups combined. This indicates that plant taxa currently account for $30 \%$ of the entire RL (including all assessment dates). Of these, 8765 are classified as trees, with respect to their growth form. Trees therefore account for $67 \%$ of plant taxa, and $20 \%$ of all taxa included on the RL (including those taxa listed as LC).

Upon examination, 7886 tree taxa were found to have been listed in 1998, primarily originating from Oldfield et al. (1998). Since then, additions of trees to the database have been sporadic (Fig. 1), ranging from zero in 2005 to 467 in 2004, the latter primarily being the result of a specific assessment of Ecuador's endemic plants (Valencia et al. 2000). Another relatively high number of accessions was recorded in 2003, largely attributable to the same Ecuadorian assessment (Valencia et al. 2000). More than half (52\%) of the 133 taxa newly listed in 2000 were derived from a specific global assessment of conifers published the year before (Farjon \& Page 1999). Overall, these results suggest that recent progress in Red Listing the world's tree species has been limited. Only 879 taxa have been

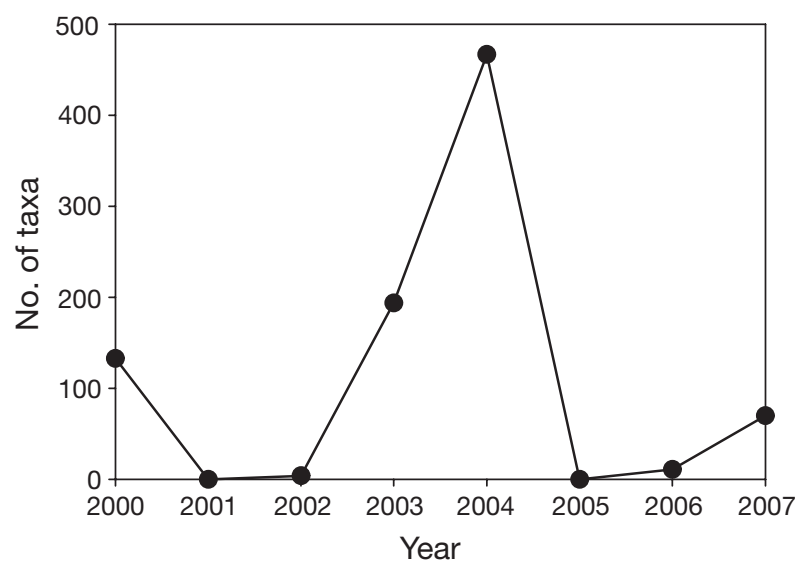

Fig. 1. Variation in the number of tree taxa included in Red List assessments undertaken from 2000 to 2007. Data from IUCN (2007). Note that no data are provided for 2001 
added to the RL database in the last decade, representing $11 \%$ of the number listed in 1998. Expressed another way, the taxa listed by Oldfield et al. (1998) combined with those added as a result of Valencia et al. (2000) account for $8324(95 \%)$ of the tree taxa currently included in the database. This apparent lack of recent progress is examined in greater depth in subsequent sections.

The IUCN Criteria and Categories currently used as a basis for RL assessments are referred to as Ver. 3.1 (IUCN 2001). As a result of the temporal distribution of accessions to the database, many of the tree taxa that are included were listed according to previous versions of the Criteria and Categories (often Ver. 2.3, as used by Oldfield et al. 1998). In order to evaluate changes in status over time, as required for example by the RLI, all taxa should be evaluated with the most recent version of the criteria. Some attempts to re-assess taxa using the latest version of the criteria have been made; for example, updated assessments of 47 conifers were included in the 2007 version of the database. Despite such revisions, most conifer taxa, along with most other tree taxa, are still listed according to earlier versions of the criteria.

Examination of the distribution of tree taxa among categories in the 2007 RL indicates that 91 are either considered to be extinct or extinct in the wild. Some 6227 taxa are considered to be threatened with extinction (i.e. combining numbers in $\mathrm{CR}$, EN and VU categories), with more than half of these classified as VU (Fig. 2). A relatively small proportion (28\%) are classified in the non-threatened categories (LC, DD and NT,

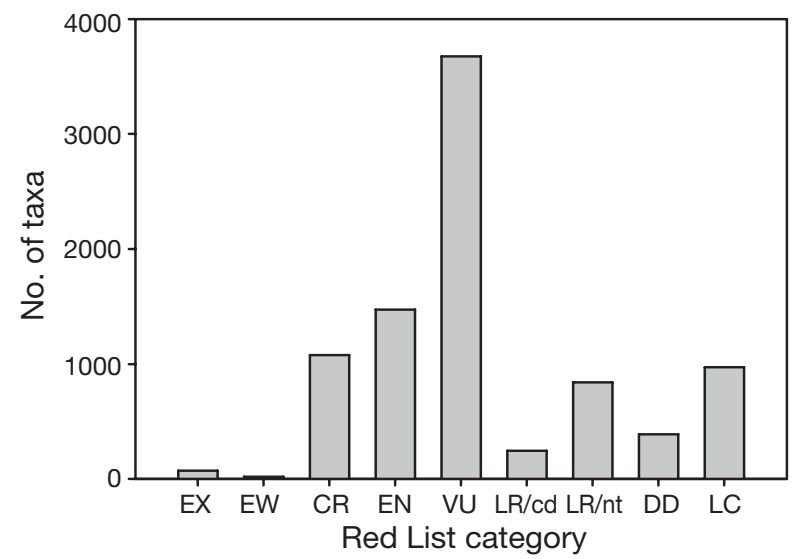

Fig. 2. Numbers of tree taxa in different Red List categories. Data from IUCN (2007). EX: extinct; EW: extinct in the wild; CR: critically endangered; EN: endangered; VU: vulnerable; LR/cd: Lower Risk (conservation dependent); LR/nt: Lower Risk (near threatened); DD: Data Deficient; LC: Least Concern. Note that categories LR/cd and LR/nt reflect listings prior to the introduction of Ver. 3.1 of the Red List criteria (IUCN 2001), as these categories were revised in Ver. 3.1. The categories LR/nt and Near Threatened (NT) are combined in this figure including their antecedents LR/cd and LR/nt), of which 389 are listed as DD (Fig. 2). This result supports the suggestion made by Nic Lughadha et al. (2005) that previous assessments have not been systematic, but have tended to focus on those taxa likely to be threatened with extinction, leading to under-representation of non-threatened categories such as LC.

The numbers of tree taxa included in the database also differ between regions. The region most represented is South and Southeast Asia, with 2511 taxa assessed, followed in descending order by South America, sub-Saharan Africa and Oceania, each with $>1000$ taxa included in the database (Fig. 3). The regions least well represented are North Africa and North Asia. It should be noted that these figures provide an indication of relative assessment effort, rather than providing an accurate impression of the relative number of threatened tree species in different regions. The 2007 RL database also provides some information on threats, which have been included for some tree taxa, but not all. The available data indicate that the vast majority of trees is considered to be threatened primarily by human-induced habitat loss or degradation (Fig. 4). For more than half of these, agriculture is considered to be the main cause of habitat loss or degradation (IUCN 2007). Substantial numbers of tree taxa are also threatened by invasive alien species, harvesting, intrinsic factors and human disturbance ( $>200$ taxa in each case; Fig. 3). Two threats, namely 'accidental mortality' (such as bycatch) and 'persecution' (such as pest control), have not yet been recorded for trees in the RL database.

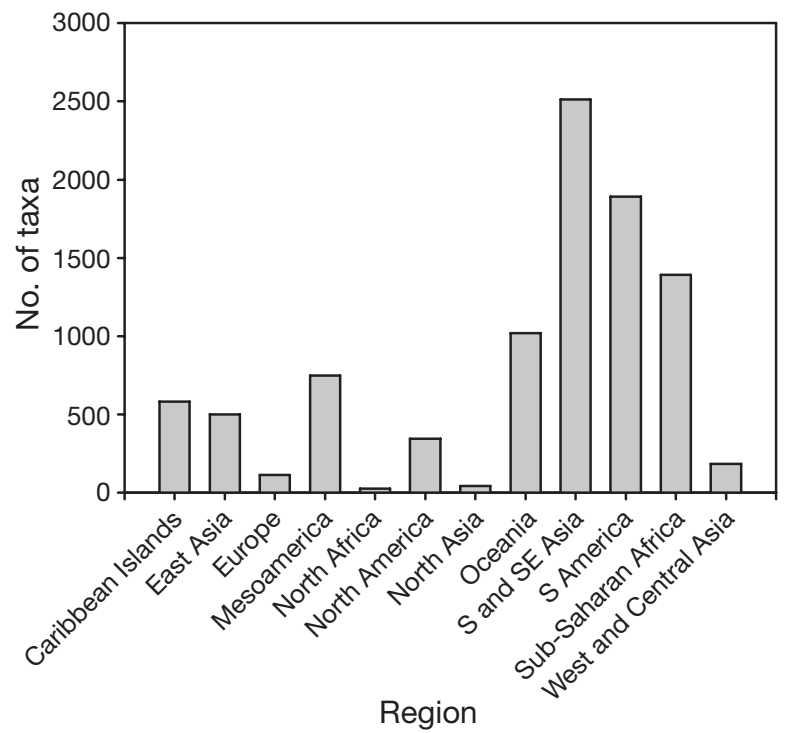

Fig. 3. Numbers of tree taxa in different geographical regions. Data from IUCN (2007). Numbers refer to all categories, including Least Concern, and therefore the numbers represent the number of taxa that have been assessed, not the numbers that are threatened with extinction 


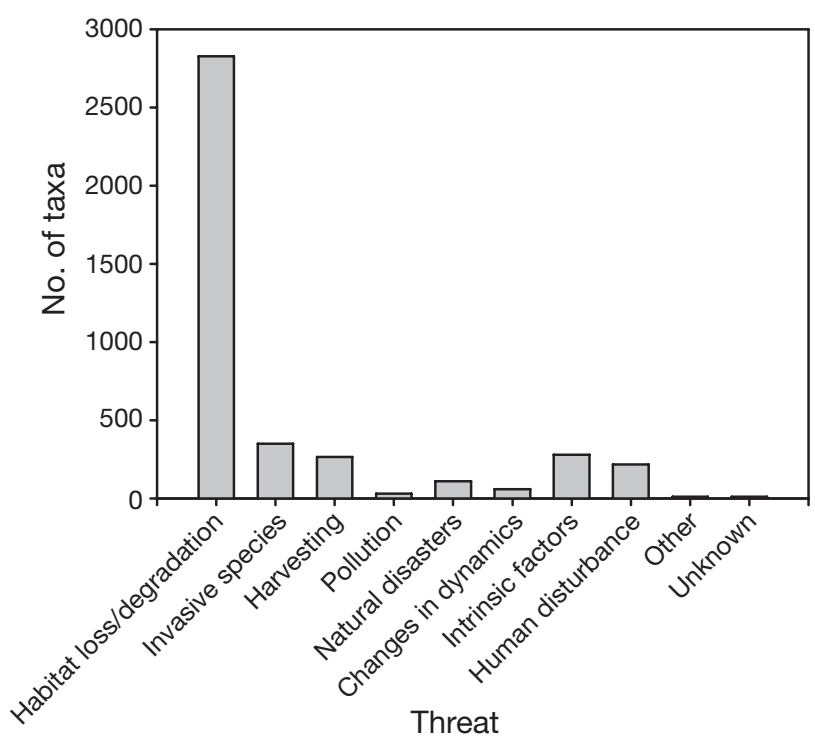

Fig. 4. Numbers of tree taxa subjected to different types of threat. Data from IUCN (2007)

\section{RECENT ACTIVITIES RELATING TO TREE RED LISTING}

In 2003, the IUCN/SSC Global Tree Specialist Group (GTSG) was established. The aims of the GTSG are to promote and implement global Red Listing for trees, and to act in an advisory capacity to the Global Trees Campaign, a joint initiative of Fauna and Flora International (FFI) and Botanic Gardens Conservation International (BGCI), which focuses on campaigning and practical action in support of tree conservation. The GTSG is currently comprised of $>70$ members, who in common with other specialist groups, undertake RL assessment activities primarily on a voluntary basis. Since 2003, the GTSG has undertaken a series of 10 assessments of different groups of trees (Table 1). These assessments varied in terms of taxonomic and geographic scope and with respect to the methods employed, enabling a comparative evaluation of the relative strengths and weaknesses of the different approaches adopted. This evaluation is presented in the following section.

The GTSG is complemented by the Conifer Specialist Group (CSG), which coordinates RL activities specifically focusing on conifers. Since the publication of the 'Action Plan' for Conifers in 1999 (Farjon \& Page 1999), amendments to the database have included periodic reassessments of a limited number of taxa as new data have become available. A project to re-assess the DD taxa was started in 2005, using the latest criteria (Ver. 3.1), resulting in a published report (Farjon et al. 2006). For the first time, herbarium and GIS data were used to support these assessments. In addition, some new taxa were assessed, most notably the new genus and species Xanthocyparis vietnamensis Farjon \& Hiep, recently described from North Vietnam (Farjon et al. 2004). Current plans include an effort to reassess all conifers using the latest RL criteria and categories, to support their use in the RLI, an initiative for which funding is currently being sought.

\section{LESSONS LEARNED FROM RECENT ASSESSMENTS}

GTSG RL assessments focusing on specific taxonomic groups have aimed to provide a global assessment of individual families (Magnoliaceae) or genera (Acer and Quercus). In each case, the objective of these assessments was to systematically apply the RL criteria to all of the taxa within each family or genus. This approach to systematically assessing taxonomic groups is recommended by Nic Lughadha et al. (2005), but has not previously been adopted for tree species, apart from conifers. Results of these assessments highlight a number of important issues. First, such assessments represent a significant task simply in terms of the number of taxa involved, values ranging from 179 taxa in the case of Acer to $>500$ in the case of Quercus. Second, these systematic assessments have highlighted the poor state of knowledge of the current conservation status of many tree species. Despite significant efforts to identify relevant sources of information and expertise, substantial proportions (14 to $60 \%$ ) of taxa were not evaluated because of the lack of sufficient information to provide any kind of assessment, even for applying the category DD.

This issue is compounded by a third problem: the uncertain taxonomic status of many tree taxa. Assessment of the Magnoliaceae, for example, was assisted by the availability of a relatively recent taxonomic checklist of the family (Frodin \& Govaerts 1996). Checklists or monographs are not available for many tree families and genera, and, as a result, the taxonomic status of many taxa is uncertain. Even in the case of the Magnoliaceae, since the publication of the checklist in 1996 several new species have been described, and taxonomic revisions have been proposed (Cicuzza et al. 2007). The lack of a stable and well defined taxonomy represents a major obstacle to the accurate RL assessments for many groups of tree taxa, and was a major contributory factor to the particularly high number of NE taxa recorded in the Quercus assessment (Oldfield \& Eastwood 2007).

Rather than assess specific taxonomic groups, 7 assessments focused on groups of trees defined on the basis of geographical or ecological characteristics. Areas 


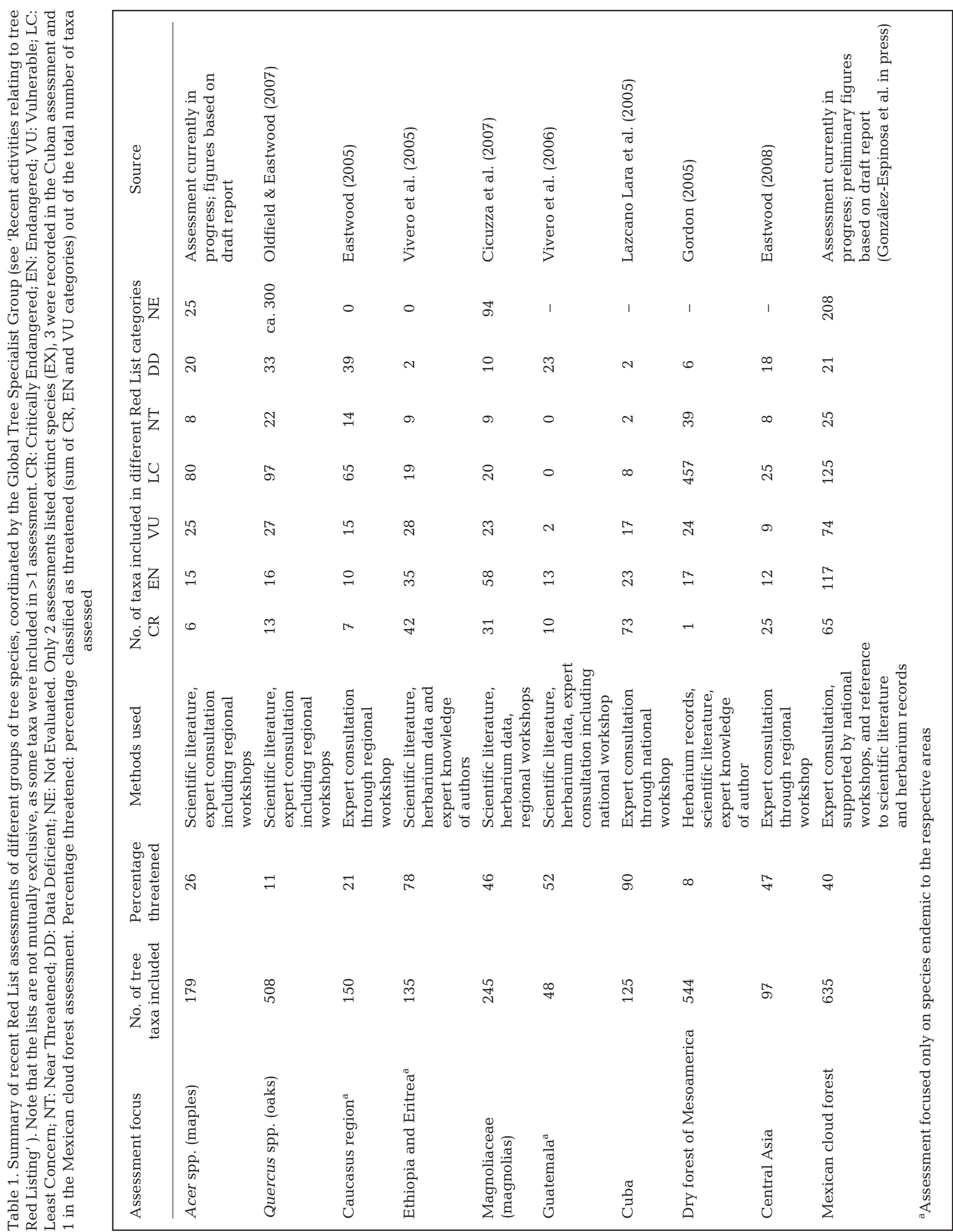


such as Central Asia and the Caucasus were targeted as they were under-represented in the previous global assessment (Oldfield et al. 1998), whereas Mexican cloud forest was targeted as this is considered to be a forest type of particular conservation importance that is under severe threat from human activities (Newton 2007), including climate change (Golicher et al. 2008). Assessments with this type of focus pose a particular challenge, as information will typically be required on taxa with a very broad range of taxonomic affinities. Global Red Listing requires that the assessment be performed across the entire distribution range of the taxon, and therefore the geographical assessments performed here typically focused on those species endemic to the area under consideration. Assessments in Ethiopia and Eritrea, for example, benefited greatly from prior efforts to list the endemic plant taxa of the region (Vivero et al. 2005). In the case where an assessment spanned several countries, such as in Central Asia and the Caucasus, consultation with different national experts in regional workshops repeatedly highlighted how perspectives of a taxon can differ from place to place, with respect to conservation status, taxonomic identity and the threats to which it is exposed.

In addition to differing in scope, assessments also varied with respect to the methods adopted. Several different sources of information can potentially inform a RL assessment of a tree taxon: herbarium data, which can be used to create distribution maps; the scientific literature, including taxonomic studies or the results of field surveys or ecological investigations; and expert knowledge, often elicited during a national or regional workshop. The assessments typically drew upon all 3 of these information sources, although to different degrees. For example, the assessments of the Magnoliaceae and Mesoamerican dry forest depended more strongly on distribution mapping based on analysis of herbarium data, whereas the assessments in Cuba, Central Asia and the Caucasus depended more strongly on expert knowledge elicited through workshops.

Each of these methods has its strengths and weaknesses. Recent trends in the RL have focused on the importance of documented quantitative evidence in making species assessments, rather than the subjective knowledge of experts (IUCN 2001). However, in practice, quantitative data on the status of many tree species are lacking, and therefore dependence on expert judgement is likely to continue in the foreseeable future. Herbarium data suffer from the problem of incomplete coverage and often reflect historic distribution patterns rather than current status. Information in the scientific literature is often fragmentary or incomplete, often providing information on selected populations, but rarely describing current abundance across the whole distributional range of the taxon. Because of the different advantages and disadvantages of these information sources, it may often be desirable to use them in combination.

The choice of assessment method might affect the results obtained. Inspection of the frequency distribution of the categories (Table 1) highlights some striking differences between the assessments. For example, the proportion of taxa that were categorized as threatened (i.e. CR, EN, or VU) varied markedly between assessments, with values ranging from 8 to $90 \%$, with an overall mean $( \pm \mathrm{SE})$ of $42 \pm 8.5 \%$. Strong dependence on either expert knowledge or mapping methods did not significantly affect the proportion of taxa in any of the categories, or the overall percentage of taxa listed as threatened (Kruskal-Wallis tests, p > 0.05 in each case). However, assessments of taxonomic groups tended to classify a higher proportion of taxa as NE than those assessments with a geographic focus (Mann-Whitney $U$-test, $\mathrm{p}=0.033$ ). This supports the suggestion that assessments of taxonomic groups tend to be more systematic and consequently include a broader range of taxa (Nic Lughadha et al. 2005).

When an RL assessment of a taxon is made, the criteria that formed the basis of the classification should also be recorded (IUCN 2001). Pronounced differences were observed in the citation of different criteria (Table 2). Most notably, Criteria B1 and B2 were each cited much more frequently than any others, by at least a factor of 3. Each of the Criteria A, C, D and E accounted for $\leq 10 \%$ citations. The $\mathrm{B}$ criteria relate to changes in geographic range, and their popularity may therefore reflect the widespread use of herbarium data and distribution maps when performing a RL assessment of tree species. For example, the assessment of Mesoamerican dry forest species, which depended almost entirely on herbarium records, exclusively applied B criteria. It should be noted that Criteria A2 and A4, which were the next most frequently cited, may also be inferred from a decline in geographic range either observed in the past (A2), or in both the past and the future (A4) (IUCN 2001). The low frequency of citations using Criteria $\mathrm{C}$ (small population size and decline) and D (very small or restricted population) suggests that relatively few tree species are very rare and/or that information on population size is generally lacking. Criterion E was cited only once, reflecting the general lack of quantitative analyses of tree taxa. Despite this bias in favour of particular criteria, there was no evidence that this had any influence on overall results. The number of criteria used in the assessment was not significantly associated with the proportion of taxa in any of the categories or the overall percentage of taxa listed as threatened (KruskalWallis test, $\mathrm{p}>0.05$ in each case). 
Table 2. Frequencies of criteria cited in Red List assessments of tree species. Note that Criterion E was cited in only 1 case for all assessments. Note also that multiple criteria may be cited for a single taxon; in such instances, each citation was considered individually. Percentage values in the bottom row, therefore, refer to the percentage of total citations (1055), not of total number of taxa assessed

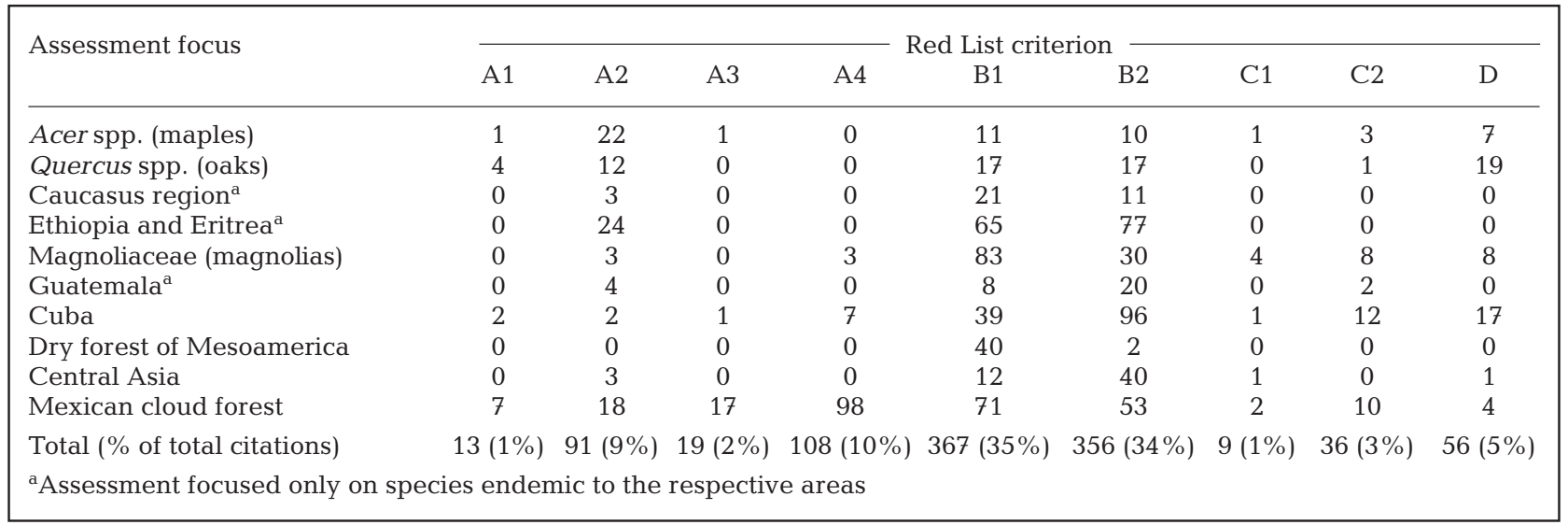

\section{FUTURE ASSESSMENTS: OPPORTUNITIES AND CONSTRAINTS}

Given the increasing use of the RL in both the development and implementation of conservation policies, as well as in environmental assessments, there is an urgent need to strengthen the amount and quality of information available, particularly for poorly documented groups such as plants. A variety of different initiatives that could contribute to this process are briefly considered here, specifically in relation to tree species. An international policy commitment for such assessments is provided by the 'Global Strategy for Plant Conservation' of the Convention on Biological Diversity, Target 2 of which calls for a 'preliminary assessment of the conservation status of all known plant species at national, regional and international levels' by 2010 (www.cbd.int/gspc/strategy.shtml). As noted above, the GTSG has taken a leading role in coordinating global RL assessments for specific groups of trees, with the CSG performing the same role for conifers. There is a need for further assessments of this type: many tree species have yet to be assessed. A number of assessments are at an early stage of development, including those for the genera Rhododendron and Diospyros (ebonies). However, the successful implementation of such assessments depends critically on the availability of financial resources and upon the availability of volunteers with the appropriate skills and knowledge who are willing to engage in the Red Listing process. As resources are limiting, there is a need to prioritise future assessment efforts. Recent activities have progressed in a somewhat ad hoc or opportunistic fashion, but the development of a more strategic approach to tree Red Listing would require provision of appropriate long-term funding.
Ideally, RL assessments should be based on a thorough, systematic field survey to provide accurate evidence of the current status of remaining populations throughout the geographic range of the taxon. In practice, this is rarely possible, and therefore assessments are likely to continue to depend on use of herbarium data and expert knowledge, as well as available survey data. In this context, greater use could be made of data collected in National Forest Inventories, as used for the RL assessment of Aquilaria spp. in Indonesia (Soehartono \& Newton 2000). Other initiatives that can contribute to strengthening the RL include the many national and regional RL assessments that are in progress, such as that provided by Valencia et al. (2000) for Ecuador.

Nic Lughadha et al. (2005) evaluated the use of herbarium data for producing RL assessments in some detail, noting that use of GIS can greatly facilitate such assessments, as demonstrated in East Africa by Willis et al. (2003). As noted by Nic Lughadha et al. (2005), evaluations using herbarium data are largely based on Criterion B, relating to geographic range, with the effect of overlooking species that might qualify as threatened under other criteria. An assessment based only on herbarium data cannot therefore be considered a complete RL assessment, but could be of value in producing a preliminary analysis. One advantage is that the process can potentially be automated, greatly increasing the rate of assessment. The primary limiting factor is the rate of conversion of relevant specimen label data into electronic records suitable for GIS analysis (Nic Lughadha et al. 2005).

Another approach is the use of the 'RapidList' method to provide preliminary assessments, by generalising the RL Categories and Criteria. Using this approach, species are classified into 3 groups, namely 
'likely threatened', 'likely not threatened' and 'likely data deficient', based on much less data than would be needed for a full assessment. The approach employs a data collection methodology to ensure that users do not input more information than is necessary to obtain a result, and makes preliminary assessments as rapid as possible. It also ensures that essential information is captured in a standard way that can be used later when full assessments are performed. An online data entry system is currently available (http://iucnsis. org/RapidList/org.iucn.rapidlist.RapidList/RapidList. $\mathrm{html}$ ), although it has not yet been extensively used for tree species.

Another initiative currently being implemented is the Sampled RL Index (SRLI) (Butchart et al. 2005). The aim is to use the RL as an indicator for monitoring the status of global biodiversity through use of the RLI, which measures trends in extinction risk based on repeated RL assessments for sets of species and enables trends in overall extinction risk to be tracked for groups of species (Butchart et al. 2004, 2005, 2007). Changes in the index reflect changes in the RL category between assessments. However, the RLI can only be applied to a taxonomic group if the majority of species in that group have been assessed. Stratified random sampling methods have therefore been developed to produce a RLI for a representative group of taxa, referred to as the SRLI (Butchart et al. 2005, Baillie et al. 2008). For plants, 1500 species of monocots and pteridophytes have been selected and are currently being assessed, and there are plans to assess other plant groups in the near future (Baillie et al. 2008). The extent to which groups of tree species will be targeted in the SRLI assessments is unclear, although there is an intention to include conifers (Baillie et al. 2008).

In addition to expanding the coverage of RL assessments, there is a need for ongoing periodic re-assessment of all the taxa already on the RL database. The current objective is for all taxa to be re-assessed at least once every 10 yr. Those taxa that are not reassessed when the $10 \mathrm{yr}$ deadline is reached are marked with a flag on the RL database to indicate that those assessments may no longer be an accurate reflection of their current conservation status, and that any supporting information may also be out of date. In 2009, 8041 plants will potentially be tagged as out-ofdate on the RL database. Much of the tree data in the RL database are now 10 yr old and require re-validation. The process of re-validating threatened assessments of numerous species could be of value in identifying how the status of species has changed in response to emerging threats such as climate change and in response to any conservation actions that have been undertaken. Re-assessment of tree taxa could also contribute to the RLI, as planned for conifers. However, the process of re-assessment represents a significant task and requires adequate resourcing.

Another issue relates to the documentation that is now required in support of RL assessments. The minimum information input that is now required includes, inter alia, a map of geographic distribution, habitat preferences, major threats, conservation measures (indicating both current and proposed measures) and data sources (cited in full) (IUCN 2001, 2008). Although most of the plant assessments have some degree of supporting documentation, only about 1000 meet the current minimum documentation requirements, largely because most of the plant assessments pre-date the introduction of the documentation requirement. Currently, none of the plant assessments on the IUCN RL include a distribution map; although paper maps have been submitted for approximately 1000 taxa, digitising these represents a substantial task and has not yet been completed.

This raises the issue of capacity within the IUCN to manage the RL database and to keep it updated. As noted by Hoffmann et al. (2008) and Nic Lughadha et al. (2005), there is a backlog of information awaiting entry into the RL database. This partly reflects the need for the relevant RL authorities to certify the data before they can be entered. Many of the appointed plant RL authorities do not have the resources or capacity to perform the evaluation work required. It is because of these problems that most of the tree RL assessments presented here (Table 1) have yet to be entered into the RL database, which consequently does not reflect all of the recent assessment activities that have taken place.

\section{CONCLUSIONS}

The RL database suggests that little progress has been made in Red Listing tree species during the last decade, but, in fact, a number of assessments have successfully been completed, and in some cases their results have been published. In total, these assessments have evaluated $>2500$ tree taxa, but only a fraction of these have so far been added to the RL database. This suggests that improvements could be made in the RL process with respect to data management and the cataloguing of new assessments as they become available. However, not all of the recent assessments have been able to provide the full documentation now required by the RL process, highlighting the problems of generating this body of information for large numbers of poorly known taxa. In this respect, many of the recent tree RL assessments must be considered preliminary in nature, as often recognised by the authors involved. 
Results of the assessments indicate that large numbers of tree species are threatened with extinction, with an average of $42 \%$ taxa classified as threatened across the 10 assessments presented here. This compares with a value of $58 \%$ for the World List (Oldfield et al. 1998) and values of 49 and $54 \%$ for mammals and birds, respectively (IUCN 2007). Given the limited coverage of tree RL assessments to date, it is likely that large numbers of tree species that are threatened with extinction still await assessment. Completing these assessments remains a substantial challenge. As recognised by Nic Lughadha et al. (2005), coverage of plants in general in the RL is currently poor, so there is an urgent need to find ways of increasing the rate and scope of the assessment process. There is a need to develop strategic priorities for future assessments of tree species, but results of recent assessments provide little evidence of systematic differences between assessments of specific taxonomic groups and those of tree taxa grouped according to geographical or ecological criteria.

In an ideal situation, an RL assessment would be performed for taxa where: (1) the taxonomy is stable and well understood, enabling rapid and accurate identification; (2) the entire geographic ranges are known with precision, both currently and in the past; and (3) the present and historic abundances are known with precision, throughout their geographic ranges. In practice, for the vast majority of tree species, these criteria are not met, and therefore the RL classification must be made with partial or uncertain data. The available information must be located, documented and pieced together, which is a time-consuming process. Despite laudable attempts to increase the rigour and objectivity of the RL process (IUCN 2001), the poor state of knowledge of the majority of the world's tree species means that Red Listing will depend strongly on expert judgement for the foreseeable future. Resources are therefore required to bring experts together to exchange information. Recent experience with tree Red Listing workshops has highlighted the value of such a collaborative approach to the assessment process. Workshops can also help build capacity to apply the RL Categories and Criteria.

A striking feature of the recent RL assessments undertaken for tree species is the relatively high use of Criteria B1 and B2, both in previous assessments (Oldfield et al. 1998) and those reported here. As noted by Nic Lughadha et al. (2005), this may result from use of herbarium data when performing RL assessments. For many taxa, herbarium data represent the only available information on which an assessment of conservation status can be based, and will therefore inevitably inform RL assessments of plants. The limited reference to other criteria largely reflects a lack of accurate field data regarding the distribution and abundance of threatened tree taxa, a situation that can only be addressed by a substantial increase in field survey activities. Current efforts at monitoring global biodiversity of plant species, and arguably for other taxonomic groups, should therefore be focused on improving primary data by undertaking systematic field surveys of specific populations (Pereira \& Cooper 2006). Ultimately, this is the only way of significantly improving the quality of the RL, and without such efforts, development of the RLI and SRLI for the majority of tree species, as well as most other plant species, appears premature.

In the absence of accurate field data, use of remote sensing and GIS technologies can be of value for producing rapid RL assessments, as noted by Nic Lughadha et al. (2005), but, again, these methods tend to focus on the use of B criteria. For example, Cicuzza et al. (2007) compiled distribution maps of Magnoliaceae species by referring to published sources, including regional and monographic floras, national Red Data Books and online herbarium specimen databases. Such distribution maps now form part of the documentation required by RL assessments. For species where precise locality data were not available, information on the political units (country, province, district) and altitude range (minimum and maximum altitude) were used to define the maximum potential range. These maps were overlaid on a map of global forest cover obtained from satellite remote sensing imagery to provide a measure of the potential area of occupancy. Data on rates of decline in forest area were derived from the GFRA (FAO 2006), enabling the B criteria to be applied. This approach could be of value to other groups of tree species, but again represents a significant workload, and for this reason the method has not yet been applied in any of the other tree assessments. As highlighted by Nic Lughadha et al. (2005), automated GIS-based approaches do not in themselves produce authoritative conservation status assessments ready for submission to the IUCN for inclusion in the Red List, but they could produce useful preliminary conservation assessments for large numbers of taxa.

Given the poor state of knowledge of most tree species, Red Listing generally has to be performed with uncertain data. As noted in the Red List guidelines (IUCN 2001), 'the absence of high-quality data should not deter attempts at applying the criteria, as methods involving estimation, inference and projection are emphasised as being acceptable throughout'. The development of such methods has attracted some attention from researchers; for example, Colyvan et al. (1999) noted that, if uncertainty is ignored, misclassifications can occur, and therefore there is a need to incorporate estimates of uncertainties in RL classifica- 
tions. In particular, use of fuzzy set theory has been proposed as a means of addressing this problem (Todd \& Burgman 1998, Regan \& Colyvan 2000, Regan et al. 2000). This approach was employed by Akçakaya et al. (2000) in their development of the RAMAS ${ }^{\circledR}$ Red List software program (Akçakaya \& Ferson 1999), which is now recommended by the IUCN Red List Programme. The method has not been widely used in RL assessments of tree species, although it could potentially be of value. Newton (in press) developed an alternative method, focusing on probabilistic analysis performed using a Bayesian Network (RLBN). Comparative analyses between RLBN and RAMAS ${ }^{\circledR}$ Red List highlighted some differences in results obtained for taxa with uncertain data, and some apparent anomalies in the output of the latter technique. This suggests that these software methods require greater testing prior to widespread deployment. Potentially, the RLBN could assist in the automation of data analysis in support of Red Listing, for example, by linking the inference engine with databases of species distribution data (Newton in press).

A final consideration is the linkage between the RL and conservation action. As noted by the IUCN (2001), the RL category applied to a species does not in itself determine priorities for conservation action; other factors such as costs, logistics, chances of success and other biological characteristics of the species should also be taken into account (IUCN 2001). The RL assessments of tree species presented here have already been used to stimulate further field assessments (for example in Central Asia), and the BGCI has subsequently undertaken comprehensive surveys of ex situ collections of magnolias and oaks as a basis for identifying gaps and for planning restoration action for CR and EN species. In this context, the role of RL assessments in gathering information about threats could be of enormous value, because the identification of appropriate conservation interventions depends critically on an understanding of the threats to which each taxon is being subjected. In their global assessment, Oldfield et al. (1998) noted that 1683 (36.7\%) tree taxa are threatened by some form of use (including felling, 'local use', or harvesting of other tree species), a similar proportion to that recorded for birds and mammals (Mace \& Reynolds 2001). Some $25 \%$ of threatened tree species have at least 1 recorded use, the most common of which is harvesting for timber (Oldfield et al. 1998). However, tree species are subjected to a variety of different threats, which often interact (Newton 2008). Widespread threats to tree species include conversion of forest to agricultural land, urban expansion, habitat fragmentation, browsing by livestock, invasive species and the use of fire (Oldfield et al. 1998, Newton 2007). For conservation action to be effective, all relevant threats must be addressed. Future RL assessments should therefore focus on systematically analysing and documenting all threats to tree species, so that appropriate conservation responses can be identified and implemented.

Acknowledgements. The assistance of the members of the IUCN/SSC Global Tree Specialist Group and of the staff associated with the FFI/BGCI/UNEP-WCMC Global Trees Campaign is gratefully acknowledged. In particular we thank Georgina Magin and Antonia Eastwood (FFI) for their activities in support of the Red Listing of tree species. We also thank Aljos Farjon for information regarding conifer assessments.

\section{LITERATURE CITED}

Akçakaya HR, Ferson S (1999) RAMAS Red List: threatened species classification under uncertainty. User manual for Version 1.0. Applied Biomathematics, Setauket, NY

Akçakaya HR, Ferson S, Burgman MA, Keith DA, Mace GM, Todd CR (2000) Making consistent IUCN classifications under uncertainty. Conserv Biol 14:1001-1013

Baillie JEM, Collen B, Amin R, Akçakaya HR and others (2008) Toward monitoring global biodiversity. Conserv Lett 1:18-26

Butchart SHM, Stattersfield AJ, Bennun LA, Shutes SM and others (2004) Measuring global trends in the status of biodiversity: Red List indices for birds. PLoS Biol 2:2294-2304

Butchart SHM, Stattersfield AJ, Baillie J, Bennun LA and others (2005) Using Red List indices to measure progress towards the 2010 target and beyond. Philos Trans R Soc B Biol Sci 360:255-268

Butchart SHM, Akçakaya HR, Chanson J, Baillie JEM and others (2007) Improvements to the Red List Index. PLoS One 2:e140

Cicuzza D, Newton A, Oldfield S (2007) The Red List of Magnoliaceae. Fauna \& Flora International, Cambridge

Colyvan M, Burgman MA, Todd CR, Akçakaya HR, Boek C (1999) The treatment of uncertainty and the structure of the IUCN threatened species categories. Biol Conserv 89: $245-249$

Donaldson JS (2003) Cycads. Status survey and conservation action plan IUCN/SSC Cycad Specialist Group. International Union for Conservation of Nature, Gland

Eastwood A (2005) Globally threatened trees of the Caucasus. A report on the Caucasus regional tree Red Listing workshop held in Tbilisi, Georgia, 26-28 Sep 2005. Fauna \& Flora International, Cambridge. www.globaltrees.org/ newgtcsite/resources.htm

Eastwood A (2008) Red List of tree species of Central Asia. Fauna \& Flora International, Cambridge

FAO (Food and Agriculture Organization) (2006) The global forest resources assessment. FAO, Rome

Farjon A, Page CN (1999) Conifers status survey and conservation action plan. International Union for Conservation of Nature, Gland

> Farjon A, Page CN, Schellevis N (1993) A preliminary world list of threatened conifer taxa. Biodivers Conserv 2: 304-326

> Farjon A, Thomas P, Duc To Luu N (2004) Conifer conservation in Vietnam: three potential flagship species. Oryx 38 : $257-265$

Farjon A, Bachman S, Gardner MF, Luscombe D, Reynolds C, 
Thomas P (2006) Conservation assessments of data deficient (DD) conifers using herbarium and Geographical Information System (GIS) data. Royal Botanic Gardens Kew/Royal Botanic Gardens, Edinburgh/Pinetum, Bedgebury

Frodin D, Govaerts R (1996) World checklist and bibliography of Magnoliaceae. Kew Publishing, Royal Botanic Gardens, Kew

Golicher DJ, Cayuela L, Alkemade JRM, González-Espinosa M, Ramírez-Marcial N (2008) Applying climatically associated species pools to the modelling of compositional change in tropical montane forests. Glob Ecol Biogeogr 17: 262-273

González-Espinosa M (ed) (in press) A Red List of the tree species of Mexican cloud forest. Fauna \& Flora International, Cambridge

Gordon J (2005) Red Listing of Mesoamerican dry forest tree species. Fauna \& Flora International, Cambridge. www. globaltrees.org/newgtcsite/resources.htm

Hassan R, Scholes R, Ash N (2005) Ecosystems and human well-being: current state and trends. Millennium Ecosystem Assessment, Vol. 1. Island Press, Washington, DC

- Hoffmann M, Brooks TM, da Fonseca GAB, Gascon C and others (2008) Conservation planning and the IUCN Red List. Endang Species Res 6:113-125

IUCN (International Union for Conservation of Nature) (2001) IUCN Red List Categories and Criteria, Version 3.1. IUCN Species Survival Commission, IUCN, Gland. Also available at: www.iucnredlist.org/static/categories_criteria (accessed in July 2008)

IUCN (International Union for Conservation of Nature) (2007) 2007 IUCN Red List of Threatened Species. IUCN, Gland. Also available at: www.iucnredlist.org (downloaded on 15 July 2008)

IUCN (International Union for Conservation of Nature) (2008) Guidelines for using the IUCN Red List Categories and Criteria, Version 7.0. Prepared by the Standards and Petitions Working Group of the IUCN SSC Biodiversity Assessments Sub-Committee in August 2008. IUCN, Gland. Also available at: http://intranet.iucn.org/webfiles/ doc/SSC/RedList/ RedListGuidelines.pdf (accessed in September 2008)

Lamoreux J, Akçakaya HR, Bennun L, Collar NJ and others (2003) Value of the IUCN Red List. Trends Ecol Evol 18: $214-215$

Lazcano Lara JC, Berazain Iturralde R, Leiva Sánchez AT, Oldfield S (eds) (2005) Memorias del primer taller para la categorización de árboles Cubanos. 11-13 Mayo 2004. Grupo de especialistas en plantas de Cuba. Fauna \& Flora Internacional and Jardín Botánico Nacional, Ciudad de La Habana

Mace GM, Baillie JEM (2007) The 2010 biodiversity indicators: challenges for science and policy. Conserv Biol 21: 1406-1413

Mace G, Lande R (1991) Assessing extinction threats: towards a reevaluation of IUCN threatened species categories. Conserv Biol 5:148-157

Mace GM, Reynolds JD (2001) Exploitation as a conservation

Editorial responsibility: Matthew Godfrey,

Beaufort, North Carolina, USA issue. In: Reynolds JD, Mace GM, Redford KH, Robinson JG (eds) Conservation of exploited species. Cambridge University Press, Cambridge, p 3-15

Miller RM, Rodríguez JP, Aniskowicz-Fowler T, Bambaradeniya $C$ and others (2007) National threatened species listing based on IUCN Criteria and Regional Guidelines: current status and future perspectives. Conserv Biol 21: $684-696$

Newton AC (ed) (2007) Biodiversity loss and conservation in fragmented forest landscapes. The forests of montane Mexico and temperate South America. CABI, Wallingford

Newton AC (2008) Conservation of tree species through sustainable use: How can it be achieved in practice? Oryx 42: 195-205

Newton AC (in press) Use of a Bayesian Belief Network for Red Listing under uncertainty. Environ Model Softw

Nic Lughadha E, Baillie J, Barthlott W, Brummitt NA and others (2005) Measuring the fate of plant diversity: towards a foundation for future monitoring and opportunities for urgent action. Philos Trans R Soc Lond B Biol Sci 360: 359-372

Oldfield S, Eastwood A (2007) The Red List of oaks. Fauna \& Flora International, Cambridge

Oldfield S, Lusty C, MacKinven A (1998) The world list of threatened trees. World Conservation Press, Cambridge

Pereira HM, Cooper HD (2006) Towards the global monitoring of biodiversity change. Trends Ecol Evol 21:123-129

Possingham HP, Andelman SJ, Burgman MA, Medellín RA, Master LL, Keith DA (2002) Limits to the use of threatened species lists. Trends Ecol Evol 17:503-507

Regan HM, Colyvan M (2000) Fuzzy sets and threatened species classification. Conserv Biol 14:1197-1199

Regan HM, Colyvan M, Burgman MA (2000) A proposal for fuzzy IUCN categories and criteria. Biol Conserv 92: 101-108

Rodrigues ASL, Pilgrim JD, Lamoreux JF, Hoffman M, Brooks TM (2006) The value of the IUCN Red List for conservation. Trends Ecol Evol 21:71-76

Soehartono T, Newton AC (2000) Conservation and sustainable use of tropical trees in the genus Aquilaria. I. Status and distribution in Indonesia. Biol Conserv 96:83-94

Todd CR, Burgman MA (1998) The assessment of threat and conservation priorities under realistic levels of uncertainty and reliability. Conserv Biol 12:966-974

Valencia R, Pitman N, León-Yánez S, Jorgensen PM (eds) (2000) Libro Rojo de las plantas endémicas del Ecuador. Herbario QCA, Pontificia Universidad Católica del Ecuador, Quito

Vivero JL, Kelbessa E, Annd Demissew S (2005) The Red List of trees and shrubs of Ethiopia and Eritrea. Fauna \& Flora International, Cambridge

Vivero JL, Szejner M, Gordon J, Magin G (2006) The Red List of trees of Guatemala. Fauna \& Flora International, Cambridge

Willis F, Moat J, Paton A (2003) Defining a role for herbarium data in Red List assessments: a case study of Plectranthus from eastern and southern tropical Africa. Biodivers Conserv 12:1537-1552

Submitted: July 30, 2008; Accepted: September 22, 2008

Proofs received from author(s): November 21, 2008 